\title{
A percepção sobre 0 trabalho em equipe multiprofissional dos trabalhadores de um Centro de Atenção Psicossocial em Salvador, Bahia, Brasil
}

\author{
Nilton Correia dos Anjos Filho ${ }^{(a)}$
}

Ana Maria Portela de Souza ${ }^{(b)}$

Anjos Filho NC, Souza AMP. The workers' perceptions about the multiprofessional team work at a Psychosocial Care Center in Salvador, Bahia, Brazil. Interface (Botucatu). 2017; 21(60):63-76.

This paper discusses the development and results of a research in a Psychosocial Care Center (CAPS) type II, in the city of Salvador-BA, in order to know the perception of the professionals about their multiprofessional team work, and specially those related to the aspects that facilitate and hinder their work. For this purpose it was adopted a qualitative approach, configured as a case study based on interviews with 21 workers of the institution. The results show that, although multiprofessional work is predominantly appreciated, there are problems of conceptualization and practice inside the team as well as complaints related to the planning conditions and management conditions and to the patterns of investment in the physical structures of the CAPS compared to the high demand of the public for this health service.

Keywords: Multiprofessional team work. Interdisciplinarity. Mental health services.
Este artigo aborda o desenvolvimento e resultados de uma pesquisa, realizada em um Centro de Atenção Psicossocial (CAPS) tipo II, do município de Salvador-BA, com o objetivo de conhecer a percepção dos profissionais integrantes da equipe sobre o trabalho multiprofissional, especialmente no que concerne aos aspectos que facilitam e dificultam esta atuação. Adotou-se, para este fim, abordagem qualitativa, configurada como estudo de caso, apoiada em entrevistas com 21 trabalhadores da instituição. Os resultados obtidos apontam que, embora o trabalho multiprofissional se apresente predominantemente valorizado, ocorrem problemas de conceituação e prática no interior da equipe, bem como a emergência de críticas relativas às condições de planejamento e gestão e ao padrão de investimento nas estruturas físicas do CAPS diante da elevada demanda do público por este serviço de saúde.

Palavras-chave: Trabalho em equipe multiprofissional. Interdisciplinaridade. Serviços de Saúde Mental. (a) Psicólogo. Rua Silveira Martins, 2555 Cabula. Salvador, BA Brasil. 41150-000. niltoncorreia_15@ hotmail.com (b) Residência Multiprofissional em Saúde, Pós-Graduação, Departamento de Ciências da Vida, Universidade do Estado da Bahia. Salvador, BA, Brasil. anaportela@ terra.com.br 


\section{Introdução}

No Brasil, desde a década de 1970, ampliou-se uma discussão sobre as políticas de saúde e de recursos humanos, tendo em vista o perfil de necessidade de saúde da população. Em tal conjuntura, destacava-se a predominância de trabalhadores de nível Superior nos serviços de saúde, mais especificamente aqueles de formação médica. Como reação, surgiram críticas quanto à formação especializada e predominantemente curativa dos profissionais de saúde, e uma necessidade de estimular a atuação multiprofissional nos serviços.

Por volta dos anos 1980, essa configuração passou a ser modificada por meio de uma nova estrutura do quadro de profissionais, que promoveu o acréscimo significativo de trabalhadores de nível médio, como os técnicos de enfermagem, e, ao mesmo tempo, alargou o campo de profissionais de nível superior não médicos, permitindo, assim, o desenvolvimento de trabalho de equipe de saúde, exercido de modo mais complexo e multiprofissional (Machado et al. ${ }^{(c)}$ apud Peduzzi'1).

No decorrer destas mudanças, inseridas no processo de redemocratização do Estado e da sociedade brasileira, destacou-se a proposta do Sistema Único de Saúde (Lei no 8.080/90), baseada nos princípios da integralidade, equidade, descentralização e participação ${ }^{2}$. As reestruturações, tanto dos estabelecimentos quanto das organizações do campo da saúde, geradas por estes novos princípios especialmente o da integralidade -, ocorreram mediante novas articulações entre os serviços e a reformulação do trabalho em equipe. Segundo Franco e Merhy³ integralidade é uma

\footnotetext{
diretriz que se organiza acionada por certos projetos terapêuticos que requisitam recursos para a assistência aos usuários, e aí forma-se o encontro entre o mundo das necessidades com os agenciamentos coletivos que operam sobre os trabalhadores certos modos de produzir o cuidado. (p. 155)
}

A mudança para uma assistência integral exige não só uma reestruturação tanto dos estabelecimentos e das organizações do campo da saúde, por meio de uma organização e articulação entre os serviços, como também a reformulação do trabalho desenvolvido pelas equipes de saúde 4 .

Para Araújo e Rocha ${ }^{5}$, a influência acerca dos diversos aspectos que compõem o processo de saúde-doença é uma consequência do trabalho em equipe. A probabilidade de um profissional se reconstruir na atividade do outro, em efeitos mútuos, é uma pressuposição das práticas interdisciplinares, tendo, assim, a finalidade de uma intervenção efetiva no contexto em que atuam. Ou seja, a prática integral ganha um conjunto de visões diverso pelos profissionais variados que formam o quadro de funcionários daquele estabelecimento de saúde.

Já para Peduzzi ${ }^{(\mathrm{d})}$ apud Peduzzi ${ }^{6}$, um tipo de trabalho coletivo é o trabalho em equipe, sendo este formado por meio da relação mútua entre as ações técnicas e a troca dos profissionais, configurando, por intermédio da comunicação, uma prática articulada e com a colaboração entre os pares.

A autora também apresenta uma tipologia não estática do trabalho em equipe, que demonstra prevalência, em determinados momentos da dinâmica do grupo de trabalhadores de dois modos: a) equipe integração, em que acontece uma costura das práticas e o intercâmbio entre os participantes; e b) equipe agrupamento, na qual se observa uma sobreposição de práticas. Para melhor caracterizar tais equipes, devem ser levados também em consideração (c) Machado $\mathrm{MH}$, Medici AC, Nogueira RP, Girardi SN. O mercado de trabalho em Saúde no Brasil: estrutura e conjuntura. Rio de Janeiro: Fiocruz/Ensp; 1992.

\footnotetext{
(d) Peduzzi M. Equipe multiprofissional de saúde: a interface entre trabalho e interação [tese]. Campinas (SP): Faculdade de Ciências Médicas, Universidade Estadual de Campinas; 1998.
} 
critérios, como comunicação, ações específicas dos núcleos profissionais, valoração social desigual da especialidade dos trabalhos desenvolvidos, flexibilização da divisão do trabalho, autonomia técnica e elaboração do planejamento assistencial compartilhado entre os membros da equipe ${ }^{6}$.

Um dos serviços de saúde que deve ter o trabalho constituído por uma equipe multiprofissional e atuar sob a ótica interdisciplinar é o Centro de Atenção Psicossocial (CAPS), sendo este um ponto de atenção do componente Atenção Psicossocial Especializada que integra a Rede de Atenção Psicossocial (RAPS). Seu objetivo é realizar atendimentos às pessoas que possuem sofrimento psíquico grave e persistente e às pessoas que possuam necessidades decorrentes do uso de drogas. Para tanto, a oferta de cuidados proposta pela equipe de trabalhadores deve ser desenvolvida por meio do Projeto Terapêutico Individual (PTI), cujo processo de construção envolve tanto a equipe quanto o usuário e seus familiares?.

Ao CAPS cabe a função de promover a reinserção social dos usuários por meio do trabalho, lazer, exercício dos direitos civis e fortalecimento tanto dos laços familiares quanto comunitários, desenvolvendo um trabalho de forma prioritária em espaços coletivos, englobando grupos, reunião de equipe, assembleia de usuários, entre outros. Possui, também, uma área territorial de atuação, e deve realizar articulações com os outros serviços ofertados por diversas redes (saúde, justiça, educação, etc. $)^{7,8}$.

O presente estudo é resultante do Trabalho de Conclusão de Curso do Programa de Residência Multiprofissional em Saúde da Universidade do Estado da Bahia (UNEB), e trata de conhecer a percepção dos profissionais de um CAPS do município de Salvador-BA sobre o trabalho multiprofissional desenvolvido nesse serviço, identificando quais os fatores que facilitam e dificultam o trabalho.

A temática demonstra uma relevância porque possibilita, aos integrantes da equipe, refletir sobre seu processo de trabalho e como este pode repercutir no cuidado dos usuários do serviço, além de proporcionar, aos que se encontram no campo da Saúde Mental, uma reflexão sobre a validade da equipe multiprofissional.

Pretende-se investigar, com base no discurso dos sujeitos da pesquisa, o processo de desenvolvimento da interdisciplinaridade neste CAPS, isto é, a troca e reconstrução permanente das práticas e saberes para obtenção de uma produção inédita de conhecimentos e atividades. Além disso, pretende-se, igualmente, buscar informações sobre a efetivação de uma abordagem integral por meio da articulação das ações, comunicação e cooperação entre os membros.

\section{Metodologia}

Os dados para esta pesquisa foram obtidos em um CAPS tipo II que oferta cuidados para pessoas com transtornos mentais graves e persistentes, podendo, também, ter como clientela pessoas que possuam necessidades devido ao uso de álcool e outras drogas, conforme a forma de organização da rede de saúde onde é localizado?.

Os critérios para os sujeitos participarem da pesquisa foram: a) compor o quadro de profissionais; e b) ter contato direto com as práticas assistenciais do serviço. Entretanto, o gerente do CAPS, em que pese não prestar assistência direta aos usuários, foi incluído neste grupo, considerando-se a importância do seu papel referente às questões clínico-institucionais e organização da unidade, que podem interferir diretamente no trabalho multiprofissional desenvolvido.

Esta pesquisa delineada em metodologia qualitativa, e definida como estudo de caso, utilizou-se da entrevista semiestruturada para a coleta de dados. Para Godoy ${ }^{9}$, o estudo de caso caracteriza-se por ter como objeto uma unidade estudada de modo profundo, com o propósito de realização de exame detalhado de um ambiente, de um sujeito, de um grupo ou de uma situação específica.

Os princípios éticos da pesquisa envolvendo seres humanos foram devidamente considerados. A coleta de dados foi realizada posteriormente à aprovação do projeto de Pesquisa pelo Comitê de Ética em Pesquisa da Universidade do Estado da Bahia. Todos os sujeitos da pesquisa tiveram acesso ao Termo de Consentimento Livre e Esclarecido e o assinaram, atendendo ao disposto na Resolução nº 466/2012 do Conselho Nacional de Saúde ${ }^{10}$. 
Desse modo, a entrevista foi composta de três partes. A primeira teve a finalidade de realizar uma caracterização do profissional; a segunda tratou de perguntas relacionadas às atividades do trabalhador; e a última abordou questões relativas à concepção do trabalho multiprofissional, como ele é desenvolvido e avaliado pelos próprios profissionais envolvidos.

Todas as entrevistas foram gravadas, transcritas e analisadas posteriormente por meio da análise de conteúdo, tendo como referência Laurence Bardin, que a define como:

Um conjunto de técnicas de análise das comunicações visando obter, por procedimentos sistemáticos e objetivos de descrição do conteúdo das mensagens, indicadores (quantitativos ou não) que permitam a inferência de conhecimentos relativos às condições de produção/recepção (variáveis inferidas) destas mensagens. ${ }^{11}$ (p. 42)

Importante salientar que, anteriormente à coleta de dados, foram formadas três categorias definidas pelos pesquisadores (caracterização do profissional, atividades desenvolvidas e trabalho em equipe multiprofissional), levando-se em consideração o roteiro da entrevista. Entretanto, após a análise dos dados, tais categorias foram revistas, passando a ter uma nova configuração: caracterização dos profissionais; atividades desenvolvidas; a concepção de trabalho multiprofissional e como ele é desenvolvido no CAPS; facilitadores do trabalho em equipe; e fatores que dificultam o trabalho em equipe.

\section{Resultados e discussão}

\section{Caracterização dos profissionais}

Foram entrevistados 21 profissionais, incluindo o gerente, sendo 18 mulheres e três homens. A média de idade dos sujeitos registrada é de quarenta anos. Quanto ao período de tempo em que atuam no serviço, a média encontrada é de seis anos. Somente quatro pessoas estão no CAPS desde a sua implantação.

A composição dos entrevistados respeitou o agrupamento realizado pela Secretaria Municipal de Saúde de Salvador referente aos CAPS municipais e conveniados/contratados, resultando na composição de participantes conforme Tabela 1.

Tabela 1. Composição dos trabalhadores participantes da pesquisa

\begin{tabular}{llc}
\hline $\begin{array}{c}\text { Profissional de Atendimento } \\
\text { Integrado - PAI (Ensino Superior) }\end{array}$ & $\begin{array}{c}\text { Técnicos em Serviço de Saúde - TSS (Ensino } \\
\text { Médio com Formação Técnica Complementar) }\end{array}$ & $\begin{array}{c}\text { Auxiliar em Serviço de Saúde } \\
\text { - ASS (Ensino Médio) }\end{array}$ \\
\hline 2 Terapeutas ocupacionais & 4 Técnicos de enfermagem & 1 Oficineiro \\
2 Educadores físicos & & \\
3 Psicólogos & & \\
2 Médicos & & \\
3 Assistentes sociais & \\
2 Enfermeiros & & \\
1 Farmacêutico &
\end{tabular}

Como já acenado, aos profissionais acima elencados acrescenta-se, ainda, o gerente com nível superior.

Dos 21 entrevistados, apenas nove possuíam algum tipo de experiência profissional no campo da saúde mental. Entre as experiências, encontram-se: docência em disciplinas sobre saúde mental em cursos técnicos; atuação em serviços do campo da assistência social com público-alvo voltado para crianças e adolescentes que possuem algum tipo de transtorno mental ou que fazem uso problemático 
de álcool e outras drogas; centro de convivência; hospital psiquiátrico; hospital-dia; sanatório; ambulatório de saúde mental; manicômio judiciário; hospital de custódia; penitenciária; e centro de referência em álcool e outras drogas. Apenas três das nove pessoas citadas possuíam experiência anterior em CAPS.

\section{Atividades desenvolvidas}

Conforme mencionado, as atividades realizadas pelos trabalhadores do CAPS são separadas em três grupos: as atividades dos PAI (Profissional de Atendimento Integrado), as dos TSS (Técnicos em Serviço de Saúde) e as dos ASS (Auxiliar em Serviço de Saúde). O primeiro grupo tem seu processo de trabalho organizado de modo que todo profissional em cada turno realize pelo menos uma atividade. Entre as ações estão as detalhadas no Quadro 1.

Quadro 1. Atividades desenvolvidas pelo profissional de atendimento integrado

\begin{tabular}{|l|}
\hline \multicolumn{1}{|c|}{ Atividades } \\
\hline Acolhimento inicial \\
\hline Oficina/grupo terapêutico \\
\hline Participação em reunião da equipe técnica e de miniequipe de referência \\
\hline Visita domiciliar \\
\hline Atendimento individual aos usuários e aos familiares \\
\hline Plantão \\
\hline Participação na assembleia com os usuários \\
\hline
\end{tabular}

Alguns profissionais ainda realizam atividades que não são desempenhadas por todos, como: matriciamento de equipes da Atenção Básica, participação na assembleia com os usuários, e algumas atividades que são específicas da sua categoria profissional, tendo, como exemplo, a psicoterapia por psicólogos e orientação de benefícios (sic) por assistentes sociais.

Dentre a atividades dos PAI, faz-se necessário destacar o profissional médico e farmacêutico, que não compartilham das mesmas atividades dos outros trabalhadores do seu grupo. A primeira categoria profissional realiza, predominantemente, atendimentos clínicos, além de visitas domiciliares e participação em reuniões técnicas. A segunda categoria realiza a dispensação, controle de validade e destinação final de medicamentos prestes a expirar, além da participação em reuniões técnicas.

No Quadro 2 encontram-se as atividades do grupo de TSS.

Quadro 2. Atividades desenvolvidas pelo técnico em serviços de saúde

\begin{tabular}{|l|}
\hline \multicolumn{1}{|c|}{ Atividades } \\
\hline Marcação de consultas médicas e auxílio ao profissional médico durante os atendimentos realizados por este \\
\hline Medicação a usuários \\
\hline Visitas domiciliares \\
\hline Ações de promoção de autocuidado \\
\hline Acompanhamento de oficinas e grupos \\
\hline Plantão \\
\hline Participação das reuniões técnicas \\
\hline
\end{tabular}


O último grupo de atividades (Quadro 3) corresponde às ações realizadas pelos ASS.

Quadro 3. Atividades desenvolvidas pelo auxiliar em serviços de saúde

\begin{tabular}{|l|}
\hline \multicolumn{1}{|c|}{ Atividades } \\
\hline Acompanhamento de oficinas \\
\hline Participação das reuniões técnicas \\
\hline
\end{tabular}

O Quadro 4 traz as informações dos entrevistados quando foram questionados sobre as atividades realizadas com mais de um profissional.

Quadro 4. Atividades com mais de um profissional envolvido

\begin{tabular}{|l|}
\hline \multicolumn{1}{|c|}{ Atividades } \\
\hline Matriciamento \\
\hline Alguns grupos/oficinas \\
\hline Assembleia com os usuários \\
\hline Alguns acolhimentos \\
\hline Visitas domiciliares \\
\hline Reunião técnica \\
\hline Miniequipe de referência \\
\hline
\end{tabular}

Para alguns, as poucas ações realizadas em conjunto são pouco elaboradas entre os membros da equipe, em virtude do tempo exíguo e quantidade de tarefas, como pode ser visualizado na fala seguinte: "Como o dia a dia é mais corrido, dificilmente eu vou falar alguma coisa da minha prática do meu grupo, da minha oficina. Na reunião nunca vai dar tempo. Então, se eu tivesse um colega fazendo comigo seria muito mais rico e funcionava muito melhor, inclusive pra todos" (S20, PAI).

Entre as atividades citadas, merece destaque a miniequipe de referência. O modo de organização de trabalho que predomina no serviço estudado é de profissional/técnico de referência, que tem o papel de construir e monitorar o PTI de um número predefinido de usuários. Nos casos em que usuários necessitem de maior intensificação de cuidado, são formadas miniequipes de referência. Entretanto, não se encontram estabelecidos nem o número de trabalhadores e nem as categoriais profissionais envolvidas.

A miniequipe de referência apresenta configuração similar à das equipes de referência propostas por Campos $^{12}$. Para o autor, tal modalidade de organização é um modo de viabilizar a interdisciplinaridade no serviço de saúde.

De acordo com tal proposição, essas equipes formadas por profissionais de categorias diferentes devem estar associadas à clientela previamente definida, de modo a possibilitar um acompanhamento contínuo e a construção de vínculo entre os profissionais envolvidos e os usuários. Nesta perspectiva estão previstos: a elaboração de PTI para alguns casos que precisam de maior cuidado, por serem mais complexos e/ou que apresentam maior vulnerabilidade; e o desenvolvimento da autonomia relacionado ao trabalho da própria equipe, além de apoio matricial quando for necessário.

Outro ponto relatado pelos entrevistados, sobretudo, pelos PAl, diz respeito às atividades pertencentes ao núcleo e ao campo. Segundo $\operatorname{Campos}^{13}$, o primeiro termo trata dos conjuntos de saberes e responsabilidades restritas a uma categoria profissional ou especialidade. Quanto ao campo, 
este é caracterizado por saberes e responsabilidades que são comuns a diversas categorias profissionais ou especialidades.

Para alguns profissionais, a inserção no CAPS traz, como consequência, uma perda parcial da sua identidade profissional, pois passam a desenvolver atividades que não são específicas do seu núcleo de competência. Entretanto, alguns trabalhadores relataram que tal perda foi sendo recuperada com o passar do tempo devido aos novos direcionamentos das ações que realizam no serviço.

\footnotetext{
“Eu era uma técnica que fazia oficinas variadas e fazia visitas, fazia acolhimento. Então eu vi que era uma atuação muito ampla que por vezes se dissolvia em outras atuações. Às vezes eu me sentia um pouco terapeuta ocupacional, assistente social, né? Eu acho isso bom por um lado e acho que com o tempo e a experiência eu fui mais moldando minha atuação mais dentro da minha área". (S11, PAI)
}

Conforme Furtado ${ }^{14}$, as atividades relacionadas ao campo são de caráter interdisciplinar e exigem uma alta interprofissionalidade, enquanto aquelas relacionadas ao núcleo se dirigem para as funções específicas de determinada profissão.

A compreensão dos profissionais desses dois termos, núcleo e campo, possibilita uma maior clareza daquilo que pode ser dividido e a certeza de que a colaboração com os outros integrantes da equipe não trará como consequência uma perda de sua identidade ou núcleo profissional ${ }^{14}$. Desse modo, os dados coletados parecem evidenciar que o não entendimento da importância da existência de atividades referentes ao campo - no caso em questão do campo da saúde mental -, além de uma busca para realização de práticas restritas às categorias profissionais, traz implicações para as ações interdisciplinares no serviço estudado.

\section{A concepção de trabalho multiprofissional e como ele é desenvolvido no CAPS}

Foram apontadas duas definições de trabalho multiprofissional pelos sujeitos. A primeira foi predominante no discurso dos entrevistados. Segundo estes, o trabalho de cada profissional com seu núcleo específico de saber/prática contribui para uma assistência global ao usuário, sendo caracterizado por uma junção de saberes com algum nível de troca entre os membros. Tais relatos a seguir exemplificam a definição citada:

"É um trabalho desenvolvido por vários profissionais de múltiplas áreas onde cada um, dentro do seu saber, dentro da sua área, pode estar contribuindo na assistência, na ajuda ao outro, ao cliente da gente, ao usuário". (S1, PAI)

\footnotetext{
"Na minha concepção, o trabalho multiprofissional, assim, é o trabalho onde cada profissional tem que fazer a sua parte dentro do seu contexto que está previsto de suas atribuições". (S4, TSS)
}

A segunda definição concebe um trabalho em conjunto de modo integrado em prol de um objetivo comum, que é o bem-estar do usuário, ocorrendo troca de saberes, articulação das ações e integração entre os membros da equipe. Nesse caso, não há perda da identidade profissional:

\footnotetext{
“O trabalho multiprofissional é você poder integrar varias áreas de conhecimento e saberes em prol de um objetivo comum. [...] E aí você tendo várias áreas de conhecimentos você consegue integrar isso em um único trabalho e faz com que você tenha mais sentido, né? Naquilo que você faz e naquilo que você consegue produzir para benefício das pessoas que sofrem com transtorno mental". (S2, PAI)
}

“Eu vejo assim que um trabalho multiprofissional ele não é só a junção de profissionais de diferentes categorias, de diferentes formações [...] Não adianta ter vários profissionais de 
categorias diferentes trabalhando no mesmo espaço se essas pessoas não dialogam. Então, eu acho que um trabalho multiprofissional tem que ter esse espaço do diálogo, da troca, do conhecimento, das discussões dos casos pra você poder compreender melhor aquele caso, poder assistir melhor aquele caso". (S9, PAI)

Percebe-se que a primeira definição acerca do trabalho multiprofissional caracteriza-se pela existência de uma multidisciplinaridade, mas que, em alguns momentos, faz referência à pluridisciplinaridade pela ocorrência de troca entre os integrantes da equipe. Quanto à segunda concepção, pode-se pensar em características tanto da pluridisciplinaridade quanto da interdisciplinaridade, embora não seja explicitado, nos relatos dos entrevistados, o nível de interação e integração entre as disciplinas e novas produções a partir delas.

Com relação ao desenvolvimento do trabalho multiprofissional no serviço, dos 21 entrevistados, 15 avaliam o trabalho da equipe de modo positivo e seis de modo negativo. Os profissionais que percebem positivamente relataram que o trabalho multiprofissional acontece de forma integrada no cotidiano do CAPS, sendo mais perceptível em momentos pontuais quando realizam atividades em que mais de um profissional participa, tais como: visitas domiciliares, reuniões da equipe técnica e de miniequipe de referência, acolhimento, grupos e oficinas terapêuticas, entre outros.

No entanto, houve ressalvas feitas pelos profissionais: alguns trabalhadores atuam em desacordo com a maioria; certos integrantes do quadro profissional apresentam dificuldades para troca de saberes e experiências; e um pequeno grupo dos membros da equipe, devido ao longo período em que trabalham juntos, realiza um trabalho de modo mais integrado e, de certa forma, similar, pois compartilham da mesma lógica da clínica que o CAPS deve possuir, diferenciando-se do restante da equipe.

Já os profissionais que avaliam de forma negativa o trabalho desenvolvido pela equipe multiprofissional apontaram que a integração entre os trabalhadores é incipiente, predominando atuações isoladas, tendo como possíveis causas: organização do processo de trabalho; comunicação ineficaz; profissionais que não compartilham totalmente o cuidado de determinados usuários com os outros colegas por serem os técnicos de referência. Todavia, o grupo também ponderou sobre outros aspectos que valorizam a experiência: o trabalho desenvolvido pelo CAPS funciona de modo mais integrado e horizontal do que em outros espaços, como, por exemplo, em hospitais, onde há um predomínio da valorização do profissional médico; e uma disponibilidade da maioria dos profissionais para o trabalho em equipe.

Como foi citado anteriormente, o CAPS deve possuir, no seu quadro de trabalhadores, diversas categorias profissionais, que têm como diretriz a atuação sob a lógica interdisciplinar? ${ }^{7}$. Para se entender melhor esta perspectiva relacionada com a percepção dos profissionais entrevistados, é necessário compreender o significado de interdisciplinaridade e de outras terminologias associadas (multidisciplinaridade, pluridisciplinaridade e transdisciplinaridade), que, muitas vezes, podem ser confundidas. Ressalta-se que a abordagem a seguir está longe de encerrar o significado de tais termos, e tem como referência os conceitos utilizados por Furtado ${ }^{14}$.

A multidisciplinaridade pode ser definida como uma justaposição de diversas disciplinas para se tratar de um mesmo tema ou solucionar um problema. Contudo, não ocorrem relações entre os profissionais de cada disciplina nem no plano técnico nem no científico.

A pluridisciplinaridade é caracterizada como um efetivo relacionamento entre as disciplinas, havendo uma coordenação por parte de uma delas ou pela direção da organização. Implica também o estabelecimento de objetivos comuns entre todas as áreas envolvidas, que deverão traçar estratégias de cooperação para alcançá-los.

Um ponto a ser destacado com relação à pluridisciplinaridade é que nela ocorre uma predominância de complementaridade em lugar de uma integração de teorias e métodos, isto é, opera mais sob a lógica de que uma disciplina deve preencher possíveis lacunas da outra. Uma clássica situação de interação disciplinar dessa concepção, por exemplo, são as famosas reuniões, para discussão de casos, realizadas pelos integrantes de várias categorias profissionais dentro de uma equipe em uma enfermaria de um hospital. 
(e) Fazenda I. Interdisciplinaridade: história, teoria e pesquisa. Campinas: Papirus; 2001.

\footnotetext{
(f) Silva DJ. O paradigma transdisciplinar: uma perspectiva metodológica para a pesquisa ambiental [Internet]. 1999 [acesso 2015 Jun 3]. Disponível em: http://www. gthidro. ufsc.br/arquivos/ transdisciplinaridade.
}

Por interdisciplinaridade compreende-se o estabelecimento de relações menos verticais entre as diversas disciplinas. Estas compartilhariam "uma mesma plataforma de trabalho, operando sob conceitos em comum". Nesse caso, não existe uma justaposição ou complementaridade entre os elementos disciplinares, mas, sim, uma combinação nova de elementos internos, com trocas entre os campos para uma tarefa ser realizada em conjunto. Desse modo, espera-se que surjam conhecimentos e posturas inéditos dos integrantes.

Para alguns autores (Fazenda ${ }^{(e)}$ apud Furtado ${ }^{14}$ ), a transdisciplinaridade seria inalcançável, apontando apenas para o entrosamento mais profundo entre as disciplinas. Outros autores consideram a transdisciplinaridade o único modo válido de interação e uma forma de transcender as limitações da interdisciplinaridade $\left(\right.$ Silva $^{(f)}$ apud Furtado $\left.{ }^{14}\right)$. Saupe et al. ${ }^{15}$ fazem ressalva, afirmando que, nessa concepção, existem fronteiras imprecisas entre as identidades das disciplinas.

Portanto, apesar de o trabalho desenvolvido pela maioria da equipe estudada estar embasado em conceitos e métodos comuns do campo da saúde mental e de se desenvolver em patamar de horizontalidade entre as categorias profissionais, alguns fatores apontados pelos entrevistados trazem, como indícios, que o trabalho multiprofissional opera de modo incipiente, circulando entre o "pluri" e o interdisciplinar. Este fato indica que as atividades profissionais são ainda pouco integradas, sendo a maioria das ações realizada isoladamente; e que, quando ocorre a interação, ela se dá em momentos pontuais no cotidiano do serviço. Tal configuração direciona mais para uma complementaridade entre as disciplinas do que para uma interação e uma nova combinação com trocas entre os campos disciplinares, sendo esta característica fundamental da interdisciplinaridade.

Para que se possa explicitar de forma mais detalhada a complexidade de um trabalho multiprofissional no CAPS, serão discutidos, nos próximos tópicos, os fatores que facilitam e dificultam o trabalho da equipe na percepção dos trabalhadores.

\section{Facilitadores do trabalho em equipe: profissionais disponíveis para a troca de saberes e práticas e comprometidos com o trabalho}

Os facilitadores do trabalho desenvolvido pela equipe, apontados pelos entrevistados, foram:

- O trabalho desenvolvido pelo apoiador institucional em saúde mental, por permitir a reflexão da prática dos profissionais e da organização clínicoinstitucional;

- O gerente do serviço que, além de ter uma boa relação interpessoal com os integrantes da equipe, consegue fazer uma gestão colegiada em busca da participação de todos no processo de tomada de decisões;

- Profissionais disponíveis para a troca de saberes e práticas e comprometidos com o trabalho desenvolvido;

- Boa relação interpessoal entre os trabalhadores;

- Reunião da equipe técnica.

Este último facilitador, segundo os entrevistados, é o principal dispositivo capaz de realizar uma maior integração e interação entre os profissionais; de possibilitar melhor discussão dos casos atendidos; de operar o planejamento e elaboração do PTI, além de permitir que sejam abordadas questões administrativas do serviço.

“Eu acho que as reuniões são necessárias porque é o único momento que toda a equipe se encontra para que a gente saiba o que está acontecendo com os usuários porque com a demanda às vezes isso não acontece". (S7, TSS) 
Durante a semana, as pautas vão sendo formuladas pela equipe e, antes da reunião, são estabelecidas aquelas prioritárias, e, igualmente, o período para seu aprofundamento. As reuniões são organizadas, geralmente, com dois pontos de pauta: 1) Informes administrativos que envolvem o funcionamento do serviço e/ou informes sobre eventos, cursos, entre outros, além de poder se abordar fatores que impliquem o trabalho da equipe ou a assistência aos usuários, e 2) Discussões de casos.

Os profissionais relataram que, nos últimos meses, tem-se discutido, também, sobre o Projeto Terapêutico Institucional do serviço, sendo conduzido, algumas vezes, pelo apoiador institucional em saúde mental do Distrito Sanitário onde o CAPS é localizado.

Sobre a participação dos profissionais nas reuniões, os trabalhadores relataram uma mudança. Anteriormente, de acordo com eles, uma parcela significativa de pessoas não comparecia à reunião, tendo como um dos principais motivos a não compatibilização do horário da reunião do CAPS com o horário de trabalho de outro vínculo profissional. Tal ausência, segundo eles, causava dificuldades para a assistência aos usuários, pois determinados profissionais que não participavam eram, na verdade, essenciais para trazer dados sobre os casos discutidos e auxiliar nas estratégias de cuidado.

No período da coletada de dados, a gestão municipal de saúde demandou que todos os gerentes dos CAPS administrados pela Prefeitura de Salvador solicitassem a participação dos servidores dos respectivos serviços nas reuniões técnicas, como uma forma de viabilizar a organização clínicoinstitucional de tais unidades de saúde. Tal direcionamento foi considerado, pela maioria dos trabalhadores entrevistados, um verdadeiro ganho na qualidade desse dispositivo para o trabalho desenvolvido em equipe.

Até o momento final da coleta, todos os integrantes da equipe já estavam participando da reunião. Acrescente-se a isto o fato de que há uma intenção da equipe de trabalho em incluir, na reunião, os trabalhadores de vigilância, com o intuito de efetuar planejamento da atenção aos usuários em situação de crise.

Todavia, a maioria dos integrantes da equipe assinalou que os maiores problemas das reuniões técnicas são os seguintes: descumprimento do que é acordado na reunião; tempo insuficiente para tratar de todos os assuntos necessários; discussão pouco aprofundada dos casos, sem utilização de textos para dar embasamento ao que é debatido; a falta de discussão de todos os casos acompanhados pela equipe, sendo abordados, geralmente, aqueles casos que exigem uma ação emergencial de toda a equipe; e dificuldade para concluir todos os assuntos iniciados.

“Falta assim... acho que numa equipe tem que ter um tempo da reunião pra definir ações porque aqui não tem. É um passando rápido pelo outro. Os diálogos nunca terminam. Começa a discutir um caso e daqui a pouco lá vem outra coisa, outra pessoa vem falando. Ninguém terminou, ninguém concluiu". (S11, PAI)

As questões apresentadas pelos profissionais sobre as reuniões técnicas revelam a importância da reflexão sistemática acerca do processo de trabalho e das ações intersetoriais, como procedimento efetivo para a construção de um cuidado integral, afastando a ocorrência de uma repetição de práticas que são, muitas vezes, fragmentadas e até descontextualizadas. A ausência ou dificuldade de desenvolver a reflexão e diálogos entre os membros da equipe multiprofissional aproxima o trabalho da lógica fundamentada tanto em uma separação das disciplinas quanto dos seus objetos de estudo e intervenção. Consequentemente, uma sensação de dissociação e desagregação pode acometer o trabalhador, chegando ao usuário, pois, apesar de um discurso ser pautado pelo conceito de integralidade, a prática na assistência é fracionada e, muitas vezes, fragmentadora de processos e até de sujeitos ${ }^{16}$.

\section{Fatores que dificultam o trabalho em equipe}

Quanto aos fatores que dificultam o trabalho em equipe, relatados pelos profissionais, foram apontados os seguintes: 
(g) Jorge MSB, Guimarães JMX, Nogueira MEF, Moreira TMM, Morais APP. Gestão de recursos humanos nos Centros de Atenção Psicossocial no contexto da política de desprecarização do trabalho no Sistema Único de Saúde. Texto Contexto Enferm. 2007; 16(3):417-25.

(h) Bichaff R. O trabalho no Centro de Atenção Psicossocial: uma reflexão crítica das práticas e suas contribuições para a Reforma Psiquiátrica [dissertação]. São Paulo (SP): Escola de Enfermagem, Universidade de São Paulo; 2006.
- Profissionais que realizam ações em desacordo com o pensamento da equipe;

- Reduzidas ações de educação permanente;

- Demanda excessiva de trabalho;

- Tempo insuficiente para desenvolvimento da reflexão e planejamento do processo de trabalho e organização do serviço;

- Carga horária diferente entre os profissionais, dificultando o encontro entre os integrantes para troca de saberes e práticas;

- Mudanças com relativa frequência da gestão do serviço e da gestão municipal de saúde;

- Organização não efetiva da reunião técnica;

- Estrutura física inadequada e falta de equipamentos, insumos e materiais;

- Pouca articulação e integração da RAPS, além de pouco quantitativo de pontos de atenção;

- Profissionais que não compartilham, totalmente, o cuidado de determinados usuários com os outros colegas por serem técnicos de referência.

Tais fatores apontam para não só para uma precarização do trabalho no CAPS estudado, mas também uma precarização do cuidado ofertado na RAPS do município de Salvador, colocando obstáculos para a efetivação das diretrizes de funcionamento da RAPS estabelecidas pelo Ministério da Saúde ${ }^{7}$. Alguns estudos têm revelado uma necessidade de maior investimento em questões relacionadas às condições de trabalho nos CAPS, com ações mais efetivas de políticas públicas direcionadas para a gestão de recursos humanos no campo da saúde mental. Para que mudanças aconteçam, acrescentam que é necessário se ter, como pressupostos, os pontos propostos pela Política de Desprecarização do Trabalho em Saúde (Jorge et al. ${ }^{(g)}$ apud Filizola et al. ${ }^{17}$; Bichaff(h) apud Filizola et al. ${ }^{17}$ ).

\section{Considerações finais}

Os dados obtidos sobre a percepção dos profissionais de um CAPS do município de Salvador-BA indicam que há, entre os entrevistados, diferenças tanto de conceituação quanto de práticas, acerca do trabalho multiprofissional nesse tipo de serviço.

A definição de trabalho multiprofissional predominante entre os trabalhadores está relacionada a uma junção de saberes e práticas das áreas disciplinares que compõem a equipe, sendo esta concepção característica da multidisciplinaridade, mas que, também, direciona a uma pluridisciplinaridade pela pontuação de uma relação entre os integrantes da equipe no nível científico e técnico. Contudo, uma parcela dos sujeitos relatou que um trabalho multiprofissional consiste em uma atuação que se realiza de modo conjunto e integrado com interação entre os membros, portanto, referenciada tanto à pluridisciplinaridade quanto à interdisciplinaridade.

Todavia, ressalta-se que estes são dados de caráter preliminar acerca do grau de interação e integração entre as disciplinas, bem como sobre novas práticas e saberes, que podem ser mais intensivamente explorados por meio de novas pesquisas.

Neste estudo, observa-se, igualmente, que, apesar de o Ministério da Saúde assinalar que o trabalho a ser desenvolvido no CAPS deve se constituir na lógica interdisciplinar, esta prática representa, até o momento, um desafio a ser superado para essa equipe estudada. 
Nos relatos dos entrevistados, é possível notar um movimento voltado em direção ao pensamento interdisciplinar, todavia limitado na prática. Entre os obstáculos podem estar: a) O fato de que a concepção do trabalho multiprofissional não se mostra compartilhada do mesmo modo por todos os membros da equipe; b) A série de alguns fatores relatados como dificuldades para a realização deste trabalho que revelam as condições de planejamento e gestão e o padrão de investimento nas estruturas físicas do serviço; e c) Profissionais que não têm total compreensão da importância das atividades pertencentes ao campo de responsabilidades/competências referentes às diversas categorias profissionais, ou seja, relacionadas ao campo da saúde mental no caso estudado.

Cabe acrescer que, apesar de predominar no serviço a organização da equipe de profissionais/ técnicos de referência, a existência de miniequipes de referência apresenta indícios de maior efetividade nos cuidados com os usuários e em ações interdisciplinares condizentes com diretrizes e princípios da Reforma Psiquiátrica.

Em suma, devido aos diversos fatores que incidem diretamente ou indiretamente sobre o trabalho em equipe multiprofissional, este representa um dos grandes desafios para a atuação no CAPS, afetando, assim, a Clínica da Atenção Psicossocial que tal serviço deve realizar.

\section{Colaboradores}

Nilton Correia responsabilizou-se pela elaboração do projeto de pesquisa, coleta e análise dos dados e produção do manuscrito. Ana Maria Portela de Souza responsabilizou-se pela orientação da elaboração do projeto, coleta e análise dos dados, assim como pela revisão do manuscrito.

\section{Referências}

1. Peduzzi M. Trabalho em equipe. In: Lima JCF, Pereira IB, organizadores. Dicionário de educação profissional em saúde [Internet]. Rio de Janeiro: EPSJV; 2009 [acesso 2015 Abr 27]. Disponível em: http://www.epsjv.fiocruz.br/upload/d/Trabalho_em_Equipe_ts.pdf

2. Paim JS. Desafios para a Saúde Coletiva no século XXI. Salvador: EDUFBA; 2006.

3. Merhy EE, Franco TB. Cartografias do trabalho e cuidado em saúde [Internet]. Tempus Actas Saude Colet. 2012 [acesso 2015 Abr 27]; 6:151-63. Disponível em: http:// www.observasmjc.uff.br/psm/uploads/Cartografias_do_Trabalho_e_Cuidado_em_ Sa\% C3\% BAde.pdf

4. Campos CEA. O desafio da integralidade segundo as perspectivas da vigilância da saúde e da saúde da família. Cienc Saude Colet [Internet]. 2003 [acesso 2015 Abr 27]; 8(2):569-84. Disponível em: http://www.scielo.br/scielo.php?script=sci arttext\&pid=S1413-81232003000200018

5. Araújo MBS, Rocha PM. Trabalho em equipe: um desafio para a consolidação da estratégia de saúde da família. Cienc Saude Colet [Internet]. 2007 [acesso 2015 Abr 27]; 12(2):455-64. Disponível em: http://www.scielo.br/scielo.php?script=sci arttext\&pid $=$ S1413-81232007000200022\&lng $=$ en 
6. Peduzzi M. Equipe multiprofissional de saúde: conceito e tipologia. Rev Saude Publica [Internet]. 2001 [acesso 2015 Abr 27]; 35(1):103-9. Disponível em: http://www.scielo.br/ scielo.php?script $=$ sci_arttext\&pid $=$ S0034-89102001000100016\&lng $=$ en

7. Lei $n^{\circ} 3.088$, de 23 de dezembro de 2011. Institui a Rede de Atenção Psicossocial para pessoas com sofrimento ou transtorno mental e com necessidades decorrentes do uso de crack, álcool e outras drogas, no âmbito do Sistema Único de Saúde [Internet]. Diário Oficial da União. 25 Maio 2013 [acesso 2015 Abr 27]. Disponível em: http://bvsms. saude.gov.br/bvs/saudelegis/gm/2011/prt3088_23_12_2011_rep.html

8. Ministério da Saúde. Secretaria de Atenção à Saúde. DAPE. Coordenação Geral de Saúde Mental. Reforma psiquiátrica e política de saúde mental no Brasil. Documento apresentado à Conferência Regional de Reforma dos Serviços de Saúde Mental: 15 anos depois de Caracas [Internet]. Brasília; OPAS; 2005 [acesso 2015 Abr 27]. Disponível em: http://bvsms.saude.gov.br/bvs/publicacoes/Relatorio15_anos_Caracas.pdf

9. Godoy AS. Pesquisa qualitativa: tipos fundamentais. Rev Adm Empr [Internet]. 1995 [acesso 2015 Abr 27]; 35(3):20-9. Disponível em: http://www.scielo.br/scielo. php?script=sci_arttext\&pid $=$ S0034-75901995000300004\&lng =en\&tlng=pt

10. Resolução n 466, de 12 de dezembro de 2012 [Internet]. Brasília (DF): Conselho Nacional de Saúde; 2012 [acesso 2015 Abr 27]. Disponível em: http://bvsms.saude.gov. br/bvs/saudelegis/cns/2013/res0466_12_12_2012.html

11. Bardin L. Análise de conteúdo. Lisboa: Edições 70; 1995.

12. Campos GWS. Equipes de referência e apoio especializado matricial: um ensaio sobre a reorganização do trabalho em saúde. Cienc Saude Colet [Internet]. 1999 [acesso 2015 Abr 27]; 4(2):393-403. Disponível em: http://www.scielo.br/scielo.php?script=sci_ arttext\&pid $=$ S1413-81231999000200013\&lng =en

13. Campos GWS. Subjetividade e administração de pessoal: considerações sobre modos de gerenciar o trabalho em equipes de saúde. In: Merhy EE, Onocko R, organizadores. Agir em saúde: um desafio para o público. São Paulo: Hucitec; 1997. p. 229-66.

14. Furtado JP. Equipes de referência: arranjo institucional para potencializar a colaboração entre disciplinas e profissões. Interface (Botucatu) [Internet]. 2007 [acesso $2015 \mathrm{Abr}$ 27]; 11(22):239-55. Disponível em: http://www.scielo.br/scielo.php?script=sci_ arttext\&pid =S1414-32832007000200005\&lng=en

15. Saupe R, Cutolo LRA, Wendhausen ALP, Benito GAV. Competência dos profissionais da saúde para o trabalho interdisciplinar. Interface (Botucatu) [Internet]. 2005 [acesso 2015 Abr 27]; 9(18):521-36. Disponível em: http://www.scielo.br/scielo.php?script=sci_ arttext\&pid =S1414-32832005000300005\&lng=en

16. Severo SB, Seminotti N. Integralidade e transdisciplinaridade em equipes multiprofissionais na saúde coletiva. Cienc Saude Coletiva [Internet]. 2010 [acesso 2015 Abr 27]; 15 Suppl 1:1685-98. Disponível em: http://www.scielosp.org/scielo. php?script=sci_arttext\&pid=S1413-81232010000700080\&lng =en

17. Filizola CLA, Milioni DB, Pavarini SCI. A vivência dos trabalhadores de um CAPS diante da nova organização do trabalho em equipe. Rev Eletr Enferm [Internet]. 2008 [acesso 2015 Abr 27]; 10(2):491-503. Disponível em: http://www.fen.ufg.br/revista/v10/n2/ v10n2a20.htm 
Anjos Filho NC, Souza AMP. La percepción del trabajo en un equipo multidisciplinario de trabajadores en un Centro de Atención Psicosocial en Salvador, Bahía, Brasil. Interface (Botucatu). 2017; 21(60):63-76.

Este artículo aborda el desarrollo y los resultados de una investigación realizada en un Centro de Atención Psicosocial (CAPS) de tipo II, en la ciudad de Salvador-BA, con el fin de conocer la percepción de los profesionales sobre el trabajo multidisciplinario en sus equipos, especialmente lo que respecta a los aspectos que facilitan y dificultan esta acción. Para ello, fue adoptado un enfoque cualitativo configurado como estudio de caso, basado en entrevistas con 21 trabajadores de la institución. Los resultados demuestran que, aunque el trabajo multidisciplinario sea, en su mayoría, bien valorado, existen problemas de conceptualización y práctica dentro del equipo. También aparecen quejas relacionadas a las condiciones de planificación y el manejo y patrón de inversiones en las estructuras físicas de CAPS frente a la alta demanda del público de este servicio de salud.

Palabras clave: Trabajo en equipo multidisciplinario. Interdisciplinariedad. Servicios de Salud Mental. 